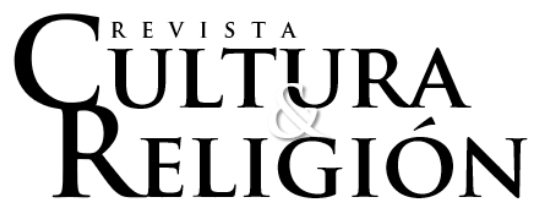

Vol. XIII, N² (2019) pp. 30-51

Recibido: 19 de julio, 2018.

Aceptado: 20 de julio, 2019.

\title{
LA RED Y LOS CÍRCULOS DE ÁNIMA. ORÍGENES, DOCTRINA Y SISTEMATIZACIÓN DE SUS FUENTES
}

\author{
The net and the circles of anima. Origins, doctrine and systematization of \\ their sources \\ por \\ Sara Pastor-Talboom* \\ Universidad Nacional de Educación a Distancia (UNED) \\ spastor@palma.uned.es
}

\begin{abstract}
Resumen
El objetivo de este artículo es mostrar los resultados de una investigación de los llamados Círculos de Ánima y de la Red de la que forman parte, explicitando sus orígenes, su doctrina y sus fuentes. Los Círculos de Ánima son los rituales que se realizan para ayudar a los seres en tránsito, es decir, las almas que tras el fallecimiento no han ascendido a la luz. El abordaje teórico es el de la antropología y, más concretamente, de la antropología de la religión y de la muerte. La observación y, especialmente, la observación participante en estos Círculos ha sido la metodología principal junto con la revisión de los múltiples canales virtuales de información y difusión de la Red de Ánima. El resultado ha sido el hallazgo de un complejo sincretismo de varios corrientes: new age, neopaganismo, teosofía, física cuántica, numerología y geometría sagrada.
\end{abstract}

Palabras clave: Círculos de Ánima, antropología de la religión, muerte, sincretismo.

\begin{abstract}
The objective of this article is to show the results of an investigation of the so-called Anima Circles and the Network of which they are a part, explaining their origins, their doctrine and their sources. The Circles of Anima are the rituals that are performed to help beings in transit,

\footnotetext{
* Doctoranda en la Escuela Internacional de Doctorado de la Universidad Nacional de Educación a Distancia (EIDUNED). Licenciada en Geografía e Historia Especialidad Antropología Cultural. Profesora Tutora del Departamento de Antropología social y cultural, Universidad Nacional de Educación a Distancia (UNED), Madrid, España.
}

Revista Cultura \& Religión Vol. XIII, 2019 № 2 (julio-diciembre)

Cómo citar este artículo: Pastor-Talboom, S. (2019). "La red y los círculos de Ánima. Orígenes, doctrina y

sistematización de sus fuentes”. Revista Cultura \& Religión.13(2). pp. 30-51. 
that is, the souls that after death have not ascended to the light. The theoretical approach is that of anthropology and, more specifically, the anthropology of religion and death. The observation and, especially, the participant observation in these Circles has been the main methodology along with the review of the multiple virtual channels of information and dissemination of the Anima Network. The result has been the finding of a complex syncretism of several currents: new age, neopaganism, theosophy, quantum physics, numerology and sacred geometry.

Keywords: Anima Circles, anthropology of religion, death, syncretism.

\section{Introducción}

El objeto de investigación ha sido una asociación sin ánimo de lucro llamada Agartam y, más concretamente, una de las redes de las que está formada, la Red de Ánima. Esta a su vez realiza, con una periodicidad aproximadamente mensual, rituales conocidos como Círculos de Ánima. La causa de su elección como tema de estudio ha sido la de profundizar en manifestaciones espirituales que escapan a la ideología dominante individualista de las sociedades occidentales urbanas y contemporáneas, en el sentido del homo aequalis dumontiano (Dumont, 1999), ya que, sin embargo, evocan nociones de la vida y la muerte, del hombre y la naturaleza, que recuerdan más a sociedades holistas o no modernas, a la manera del Homo Hierarchicus (Dumont, 1970). Los Círculos de Ánima son los rituales que se realizan para ayudar a los llamados seres en tránsito, es decir, ánimas que tras el fallecimiento no han ascendido a la Luz. Su fin principal es la ascensión de estas almas o ánimas pero también, de forma subsidiaria, la ayuda al duelo de los asistentes que lo requieran.

El abordaje teórico es el de la antropología. Por un lado, se ha seguido durante la investigación el debate sobre la tensión entre religión y espiritualidad (López Novo, 2012; Heelas \& Woodhead, 2005; Fuller, 2001), como una forma de oposición entre 'creencias' y 'epistemología' respectivamente (Luhrmann T. M., 2018; López-Pavillard \& Blanes, 2017; Koss-Chioino, 2010; Turner, 2003). Por otro, y en cuanto a su temática, este estudio se enmarca en el campo de la antropología de la muerte (Robben, 2017; García Hernández, 2008Di; Di Nola, 2007; Thomas, 1983).

Esta asociación llamada Agartam (Agartam, 2009) está formada por diversas redes. Se trata de la Red de Meditaciones de Luna Llena (la más antigua y pilar de Agartam desde sus inicios), la Red de Ho'oponopono, la Red de Ánima, la Red Reunión Café, la Red Imágenes del Alma, la Red de Sonido, la Red Cree en ti, la Red Essentia, la Red de Prosperidad, la Red Encuentros de Luz, la Red Arcoiris, la Red Agartam Educación, la Red Cristal, la Red Samsara y, finalmente, la Red de Reiki. Estas redes han ido apareciendo

Revista Cultura \& Religión Vol. XIII, 2019 № 2 (julio-diciembre)

Cómo citar este artículo: Pastor-Talboom, S. (2019). "La red y los círculos de Ánima. Orígenes, doctrina y sistematización de sus fuentes”. Revista Cultura \& Religión.13(2). pp. 30-51. 
progresivamente, a medida que algunos miembros de la asociación han querido encargarse de su coordinación. Tienen en común una serie de valores que definen de forma global Agartam, y que aparecen en su página web a modo de ideario. Son el amor, el respeto, la firmeza con amor, la integración, la confianza, el propósito, el trabajo en equipo, el altruismo y la unidad. Que sean nueve no es casualidad, como se verá a continuación.

La fundadora de Agartam es la abogada y asesora fiscal, de origen sevillano y afincada en Barcelona (España), Alicia Sánchez Montalbán. Por tanto la asociación se originó en Barcelona y de ahí se ha extendido por el resto del estado español y, contemporáneamente, por Sudamérica. En palabras de Alicia Sánchez:

Agartam nació poco a poco, sin que los que comenzábamos a materializarlo nos diéramos cuenta de lo que estaba naciendo. Un impulso inicial de crear un centro de terapias para ayudar a los demás, con lo que cada uno sabía hacer; un nombre canalizado [Agartam], cuyo significado no entendíamos muy bien; un número [el nueve] y un símbolo [nueve puntos unidos en red], sugeridos en meditación por los guías espirituales que acompañaron el nacimiento de Agartam... Piezas de un puzzle incompleto, que perdió fuerza cuando los que estábamos allí tomamos rumbos diferentes.

El nombre, el número y el símbolo quedaron ahí, latentes en mi interior, a la espera de que se produjera la magia que les diera sentido. Mientras me abría paso entre las brumas de mi conciencia, que poco a poco despertaba, y afrontaba las lecciones que la vida me proporcionaba, una noche recibí el encargo de realizar una meditación en la siguiente luna llena. Una parte de mí protestó: ¿quién era yo para guiar una meditación? La otra parte se sintió ilusionada, y por eso decidí confiar.

Llevé a cabo el encargo a principios del verano del 2009 y descubrí, mientras sucedía, que no sólo sentía ilusión sino también plenitud. Eso me animó a convocar para la siguiente luna llena a los que asistieron, y se inició así una andadura que llenaría mi vida de satisfacción y de gozo. Confiar en aquel encargo y en la llamada de mi corazón me ayudó a descubrir mi propósito de vida y a materializar algo que nunca había planeado, al menos de manera consciente. Tal vez, mi alma sí conocía ese plan, pero mi mente no lo recordaba.

En el nacimiento de Agartam conté con el apoyo de grandes personas, grandes amigas que me ayudaron a confiar en mí misma y en todo lo que estaba sucediendo. [...] ellas estuvieron conmigo, ofreciéndome su amor para reconfortarme y ayudarme a resurgir. Siempre les estaré inmensamente agradecida porque ellas, de ese modo y aportando su sentir, también fueron las fundadoras de $\operatorname{Agartam}^{1}$. [...] Creados los pilares iniciales con la meditación de luna llena [...], comenzaron a llegar hasta nosotros personas que deseaban ayudar, que resonaban con el mensaje que Agartam [...] (Sánchez Montalbán, 2016, s. p.)

No se han encontrado estudios previos sobre esta asociación. Los frentes por tanto son múltiples. Nos interesa el reto que supone la investigación 'académica' de una epistemología que no lo es en absoluto, refiriéndonos con esta afirmación a la base no

\footnotetext{
${ }^{1}$ Una de estas amigas sería Karina Zarfino, que resonó con su mensaje, grabó los primeros videos y llevó Agartam a Sudamérica.
}

Revista Cultura \& Religión Vol. XIII, 2019 № 2 (julio-diciembre)

Cómo citar este artículo: Pastor-Talboom, S. (2019). "La red y los círculos de Ánima. Orígenes, doctrina y sistematización de sus fuentes”. Revista Cultura \& Religión.13(2). pp. 30-51. 
cientificista de las asunciones de Agartam; la proporción tan alta de mujeres frente a hombres; la imbricación en creencias posmodernas... El interés de este artículo y que conforma los siguientes epígrafes, es la exposición del origen de la Red de Ánima, la explicitación de sus visiones ontológica, vital y doctrinaria, el hacer partícipe al lector de lo que es un 'círculo de ánima' como ritual y, finalmente, el sistematizar sus fuentes.

La investigación se inició en abril de 2016. La metodología conllevó la observación y la observación participante en una veintena de Círculos, en algunos de los cuales se realizaron fotos, registros de audio y vídeos. Se realizaron historias de vida de la fundadora de Agartam y de las principales líderes. Las entrevistas fueron abiertas e informales, buscadas y espontáneas, en este caso a los organizadores de los Círculos de la Red de Ánima como a los asistentes anónimos a las sesiones, y en los lugares de realización de los rituales. En cuanto a los grupos de discusión, estos se desarrollaron con los asistentes a los Círculos como con los inscritos en los cursos de formación ofertados por Agartam. Se escribió un diario de campo.

Fueron utilizadas su página web y redes sociales (You Tube, Facebook, Twitter, Instagram, incluso grupos y listas de distribución de Whatsapp). Se procedió a la búsqueda y lectura bibliográfica y webgráfica. Finalmente se realizó el curso de Ánima que habilita para poder crear un Círculo propio y ser su mediadora/canalizadora, ofertado por la fundadora de Agartam, y que constituyó una vía privilegiada de contacto y acceso a sus fuentes.

\section{1. ¿Cuándo empezó Ánima?}

Si Agartam nació en julio de 2009 y se subdividió en varias redes, la Red de Ánima en concreto surgió tres meses después, en septiembre del mismo año. Alicia Sánchez narra en primera persona (Sánchez Montalbán \& Polo, 2016) cómo ocurrió. La fundadora estaba impartiendo el curso Aprender a Canalizar en Mataró (Barcelona, España), curso que todavía imparte en la actualidad (Sánchez Montalbán, 2018). La fundadora de Agartam cuenta que en esa época aún sentía miedo e inseguridad ante la presencia de seres en tránsito y, que a consecuencia de ello, había pedido a los arcángeles que no permitieran la entrada de ninguno durante el curso. Pero,

Ese día, el pacto no funcionaba. Desde el principio, la sala estaba llena de almas en tránsito y, casualmente, dos de las participantes las veían.

-¡Uf! Esto está llenito- decían.

-Me duele mucho el hombro desde hace un rato- se quejaba un chico.

- ¿Claro! -aseguraban ellas-. Tiene ahí a una anciana apoyada.

-Me llora mucho este ojo- murmuraba otro.

Enseguida, ellas replicaban:

-Claro. Hay un señor con barba pegado a tu cabeza.

Revista Cultura \& Religión Vol. XIII, 2019 № 2 (julio-diciembre)

Cómo citar este artículo: Pastor-Talboom, S. (2019). "La red y los círculos de Ánima. Orígenes, doctrina y

sistematización de sus fuentes”. Revista Cultura \& Religión.13(2). pp. 30-51. 
Yo no podía creer lo que estaba pasando. Aquellas dos chicas, que eran hermanas, no tenían ninguna duda. Además, la energía estaba enrarecida. El curso se desarrollaba de manera lenta y ardua.

Interiormente les pregunté a los arcángeles:

-Pero, ¿qué me estáis haciendo? ¿No teníamos un pacto?

Y ellos, tranquilamente, respondieron:

Ya lo comprenderás.

Pero el curso avanzaba y aquello seguía igual. Yo me sentía responsable de la situación. ¿Cómo iba a dejar que los participantes se fueran a casa con almas en tránsito enganchadas a sus auras? Cada vez que lo pensaba, el arcángel Miguel se acercaba a mí para susurrarme:

-Serénate. Todo está bien. No eres responsable de lo que está pasando. Tiene que pasar. Ya lo comprenderás.

Como yo sabía que, cuando los guías dicen eso, no van a aclararte nada más hasta que llegue el momento adecuado, intentaba relajarme y confiar.

El curso llegaba a su fin y las almas en tránsito continuaban interfiriendo en los participantes. Durante la última meditación sentí que el arcángel Miguel me decía con firmeza:

-Ha llegado tu momento. Prepárate.

Minutos antes de que se acabara la sesión, uno de los asistentes propuso:

-¿Por qué no les ayudamos a ir a la Luz?

Se me erizó la piel. Yo no sabía cómo hacer aquello. Sólo había visto a alguien hacerlo, una sola vez.

En el silencio que se generó en la sala, a la espera de mi respuesta, escuché con claridad la indicación del arcángel:

-Ahora. Tu momento es ahora.

Supe entonces que había llegado aquello que estaba evadiendo, que tendría que afrontar el miedo y decidirme a avanzar, a pesar de él. No demasiado convencida dije:

-Bueno. La verdad es que yo no sé cómo se hace eso, pero sí sé que el arcángel Miguel está aquí y me está guiando. Así que, de acuerdo, hagámoslo. Vamos a ayudarles.

Nos pusimos en círculo y nos tomamos de las manos. Cerramos los ojos para relajarnos y concentrarnos. Al poco, yo empecé a repetir las palabras que el arcángel me dictaba.

-Hermanos que os sentís perdidos, acudid a este círculo. Queremos ayudaros. Vamos a crear un tubo de luz hasta la Fuente, en el centro de este círculo, para que podáis regresar a casa. Animaos a pasar. Entrad en su interior. En él os sentiréis reconfortados. Recuperareis la paz y la alegría. Hermanos, os amamos. Pasad al centro del círculo. Os amamos...

La palabra "hermanos" y la afirmación "os amamos" se repitieron muchas veces durante la sesión, que duró casi una hora y media. Muchas almas se elevaron. Se resolvió, incluso, una situación de estancamiento que bloqueaba a una de las participantes del curso. Aquella chica no había podido canalizar. Su padre, que había fallecido unos años antes, seguía con ella, intentado que comprendiera que él la quería.

Fue tan emocionante, enriquecedor y grato que todos, incluida yo, quedamos maravillados. El agradecimiento que aquellos seres nos había mostrado nos abrió de par en par el corazón. Queríamos más. La sensación era común. Enseguida se me ocurrió proponerlo:

- ¿Por qué no nos reunimos una vez al mes, como se hace con las meditaciones de luna llena, y les ayudamos?

Dijeron que sí y comenzó, de ese modo, Ánima. (Sánchez Montalbán \& Polo, 2016, pp. 202-205)

En el momento de escribir estas líneas, nueve años después, Agartam está formada por 15 Redes y está presente en 12 países (Agartam Argentina, Agartam Chile, Agartam Colombia, Agartam Costa Rica, Agartam España, Agartam Francia, Agartam México,

Revista Cultura \& Religión Vol. XIII, 2019 № 2 (julio-diciembre)

Cómo citar este artículo: Pastor-Talboom, S. (2019). "La red y los círculos de Ánima. Orígenes, doctrina y sistematización de sus fuentes”. Revista Cultura \& Religión.13(2). pp. 30-51. 
Agartam Paraguay, Agartam Perú, Agartam Uruguay, Agartam USA y Agartam Venezuela) con sus respectivas coordinadoras (sólo dos son hombres) y más de 500 grupos en total (Agartam, 2018). A parte de su página web (Agartam, 2009) hacen un uso considerable de las redes sociales (Facebook, Twitter, Instagram, You Tube, Linkedin), de la colaboración con el canal de radio y televisión Mindalia y, desde mayo de 2018, han publicado electrónicamente y por primera vez la Revista Agartam (Agartam, 2018). La impresión es la de una asociación que va in crescendo, a pesar de que sus componentes puedan tener trayectorías en zigzag, con salidas y reentradas en la asociación.

Específicamente el objeto de estudio, es decir, la Red de Ánima y sus Círculos está extendida por España, Perú, Argentina, Chile, Colombia, Uruguay y EEUU (Miami) (Agartam, 2009).

\section{Doctrina}

Para hacer un resumen de su doctrina se tendría que empezar por las concepciones que tienen de la idea de persona. Esta está formada por la trilogía alma, cuerpo y conciencia. El alma (el espíritu) es el ente inmortal y por tanto perenne, mientras que la encarnación y reencarnación corporal es temporal. Con cada vida corpórea elegida previamente por el alma para su aprendizaje y evolución (con un propósito de vida), el alma adquiere una conciencia. Precisamente es tarea de los movimientos neoerianos, como el objeto de estudio, la llamada al despertar de la conciencia, para que recuerde su propósito de vida, y se eleve. De esta manera los seres humanos conviven entre ellos con conciencias elevadas algunos, y otros bajas. Desde este punto de vista, la muerte es el abandono del alma del cuerpo, llevándose con ella la conciencia de esa vida, con todo lo que ha aprendido. A pesar de que la conciencia es temporal y el alma eterna, es la conciencia la que rige tanto en vida como tras la muerte, y permite al alma que tras el deceso ésta vaya a la luz (lo más frecuente) o que se quede anclada en esta dimensión (Sánchez Montalbán \& Polo, 2016).

Se ve al ser humano como un ser energético multidimensional, compuesto por varios cuerpos energéticos: el físico-etérico, el emocional, el mental, el astral y el causal. En cada plano o dimensión se tiene un cuerpo u otro. Entre estos planos destaca el plano astral: el lugar o estado donde se tralada la conciencia inmediatamente después de la muerte física (Mateos, 2016). Dentro del plano astral hay gradientes. En el bajo astral están los seres densos, con energía emocional y mental negativa, muy cercanos al plano físico porque no quieren trascender o soltar aquello que dejaron. Sólo a medida que van comprendiendo y liberando van ascendiendo al alto astral, del que finalmente saldrán para pasar al siguiente plano o dimensión. Los seres del bajo astral pueden ser seres con conciencia (ya sean seres en tránsito, sujetos de ayuda por parte de los Círculos de Ánima, ya sean seres propios de esas dimensiones densas y que existen porque son necesarios en la dualidad bien/mal) o seres sin conciencia (egrégores o acumulación de energía muy densa creada con el pensamiento). En las dimensiones más sutiles y cercanas a los seres humanos $\left(4^{\mathrm{a}}, 5^{\mathrm{a}}, 6^{\mathrm{a}}\right.$ y $\left.7^{\mathrm{a}}\right)$ existen seres

Revista Cultura \& Religión Vol. XIII, 2019 № 2 (julio-diciembre)

Cómo citar este artículo: Pastor-Talboom, S. (2019). "La red y los círculos de Ánima. Orígenes, doctrina y sistematización de sus fuentes”. Revista Cultura \& Religión.13(2). pp. 30-51. 
de luz cuya misión es ayudarnos a evolucionar en las nuestras, las $3^{\mathrm{a}}$ y $4^{\mathrm{a}}$ dimensión: guías espirituales (seres que han experimentado vida humana y que ya se han elevado), maestros, ángeles, arcángeles y seres crísticos (Mateos, 2016; Sánchez Montalbán \& Polo, 2016).

Basándose en autores como Brian Weiss (2005) o Elisabeth Kübler-Ross (2012, $2011)^{2}$, se defiende que no somos seres humanos con experiencias espirituales sino seres espirituales con experiencias humanas. Cuando el cuerpo muere, el alma empieza un proceso de comprensión, desapego y liberación hasta la fusión con el Amor Infinito. Se imagina este proceso como si fuera un recorrido por los diferentes colores del arcoiris o por los distintos chacras de nuestro ser y, al haberlos comprendido y trascendido todos, se llega al estado de la luz blanca, que es la unión de todos los colores (Mateos, 2016). Es interesante además la frecuente utilización de la imagen de la mariposa como metáfora del proceso vida/(no)muerte (Mateos, 2016; Kübler-Ross, 2011; Agartam, 2009).

¿Por qué hay seres que se anclan en el plano astral o no van directamente a la luz? Según la coordinadora de la Red de Ánima, Carol Mateos (2016), los motivos son varios:

- Apegos a cosas materiales (una casa, un espacio, un objeto, dinero, etc.).

- Apegos o ataduras emocionales y/o mentales que los atan con seres queridos o que les hacen sentir que tienen cuestiones pendientes por resolver (aquí estarían los sentimientos o energías de culpa).

- En traspasos repentinos, bruscos o violentos, cuando la conciencia no sabe qué es lo que está sucediendo.

Por su parte, Alicia Sánchez (Sánchez Montalbán \& Polo, 2016) reelabora ligeramente esta tipología de las almas en tránsito distinguiendo:

- Situaciones de estancamiento leves y que pueden resultar de fácil situación en los Círculos de Ánima. Aquí se encontrarían las almas que se quedan atrapadas porque no saben que han muerto, por culpa, por miedo, por rencor o rabia, por apego y por tristeza o depresión.

- Almas de personas que se suicidaron. Cuando eso sucede el alma queda en tránsito porque la conciencia no asumió el aprendizaje y se queda inmersa en la culpa.

- Situaciones de estancamiento que se prolongan en el tiempo. Estas son más complejas ya que cuanto más tiempo pasa el alma en el bajo astral su conciencia se va volviendo cada vez más densa. En estos casos el alma puede incluso transformarse hasta adoptar la forma de un insecto, una rata o una apariencia muy desagradable. También estarían

\footnotetext{
${ }^{2}$ Elisabeth Kübler-Ross (1926-2004) fue una psiquiatra especializada en estudios sobre la muerte y los cuidados paliativos. Dedicó más de 25 años a investigar la experiencia final de la vida de enfermos terminales. Birian Weiss (1944-) es psiquiatra, creyente en la reencarnación y partícipe de las llamadas terapias regresivas a vidas pasadas.
}

Revista Cultura \& Religión Vol. XIII, 2019 № 2 (julio-diciembre)

Cómo citar este artículo: Pastor-Talboom, S. (2019). "La red y los círculos de Ánima. Orígenes, doctrina y sistematización de sus fuentes”. Revista Cultura \& Religión.13(2). pp. 30-51. 
en esta tipología las almas prisioneras de otra conciencia, normalmente por haber tenido muy baja autoestima en vida.

\section{Cómo se elabora un Círculo de Ánima}

A continuación, se van a enumerar los pasos que se siguen para crear un Círculo de Ánima. Para ello este apartado se va a basar en parte del material facilitado por Carol Mateos (2016) en los Cursos de Ánima, cursos dirigidos a formar a futuros mediadores en tales círculos, y que se ha tenido ocasión de corroborar mediante la observación participante. De hecho, Carol Mateos fue la Coordinadora de la Red de Ánima desde su fundación en 2009 hasta 2016. Después ha seguido una línea independiente de Agartam y el testigo ha sido recogido por otro coordinador, en este caso argentino, y por la propia Alicia Sánchez Montalbán.

En primer lugar, se prepara la sala donde se va a realizar el círculo poniendo cuatro cuarzos turmalinas en las esquinas, preferentemente esferas. En el centro, el altar: un cuarzo canalizador $^{3}$ en el medio, los cuatro elementos de la tierra (agua, una vela, una plantita e incienso del arcángel Miguel) y cualquier otra cosa que se desee poner para ayudar a la realización del círculo.

Cuando están todos los asistentes, y sentados en sillas o sobre cojines y en círculo, se empieza a explicar qué es Ánima y cómo funciona con el fin de equilibrar y armonizar las energías del círculo, tanto de los asistentes como de los seres en tránsito. La charla inicial sugerida por Carol Mateos que sigue el/la mediador/a es la siguiente (Mateos, 2016):

Ánima es un Círculo de sanación y de luz creado por la unión y el amor de las personas que se reúnen. Se sustenta por energías de elevada vibración como el amor y el respeto entre otras, en el que, principalmente, se ayuda a seres en tránsito a que se dirijan a su lugar: la Luz, fuente de amor infinito. Además de esta función principal, Ánima es también un lugar de sanación para aquellas personas que participan en el círculo. Mientras abrimos el corazón para ayudar a que otros seres se sanen, a la vez permitimos que ese mismo amor obre en nosotros y nos sane.

Es un círculo en el que se acompaña a las personas en proceso de despedida y de duelo, ofreciendo un entorno que ayuda a liberar a través de la comprensión y el perdón los bloqueos emocionales y mentales, tanto de los seres en tránsito como de los seres queridos que quedan en esta realidad. Es un portal que permite la conexión entre diferentes niveles de conciencia o dimensiones. En el círculo conectamos con nuestra propia divinidad para comunicarnos tanto con nuestros guías y seres de alta vibración que nos guían y asisten, como con seres o almas que se quedaron anclados en su proceso de transición. Es un espacio muy luminoso y protegido.

\footnotetext{
${ }^{3}$ En este apartado recogemos en cursiva las voces nativas o emic.
}

Revista Cultura \& Religión Vol. XIII, 2019 № 2 (julio-diciembre)

Cómo citar este artículo: Pastor-Talboom, S. (2019). "La red y los círculos de Ánima. Orígenes, doctrina y sistematización de sus fuentes”. Revista Cultura \& Religión.13(2). pp. 30-51. 
Se realiza con total respeto y amor hacia los seres en tránsito que se personan, y no se les obliga a pasar o trascender si no lo desean. Principalmente porque aquello que les ancló debe ser comprendido y sanado con amor para que el tránsito pueda ser realizado. A veces los seres en tránsito necesitan comprender qué les sucedió, o incluso desean transmitir algún mensaje a sus seres queridos por lo que en algunas ocasiones se dialoga con ellos. En esta Nueva Era, el ser humano utiliza como herramientas para evolucionar el Amor, la Unión, el Respeto, la confianza, la libertad entre otras. El tiempo en que nuestra alma aprendió a través del miedo o la separación quedó atrás y es hora de sanar e integrarlo todo para avanzar.

El Círculo que creamos está rodeado por nuestros guías espirituales, maestros, seres de luz que nos apoyan en esta labor, ángeles, arcángeles, y por la fuerza del Arcángel Miguel que nos guía y nos cuida. Su energía aporta fortaleza, luz y amor para trascender los bloqueos. Hay que tener en cuenta que estos seres a los que queremos ayudar, en el momento de traspasar, no pudieron o quisieron llegar a la Luz, ya sea porque existen vínculos energéticos emocionales y mentales que los atan y limitan, porque no se sienten merecedores de la Luz y necesitan liberarse de cargas, o porque tiene cuestiones pendientes de resolver.

Estos seres a veces vibran con una energía que quizás nos puede asustar (miedo, rabia, tristeza...) pero recordemos que son hermanos que, aunque se encuentren en otro plano, se sienten perdidos y necesitan el amor, la comprensión, la firmeza y el respeto para sanar y trascender.

Todos estamos conectados con la Fuente. Todos procedemos de ella y a ella nos dirigimos. Lo más importante para ayudar a estas conciencias es escuchar con el corazón, algo que todos sabemos hacer. Cada persona escucha su canal y recibe información sobre lo que sucede. A través de las percepciones de cada uno de los participantes que forman el círculo, se crea una especie de collage de información que da sentido a lo que está sucediendo. Por tanto, la fuerza no proviene de una sola persona o de las capacidades psíquicas que tenga más desarrolladas, sino del amor y la unión de todos los componentes del círculo.

A continuación, se inicia una meditación de apertura, con los ojos cerrados y las manos cogidas, y que sigue las siguientes directrices del/la mediador/a (Mateos, 2016):

- Realizamos tres respiraciones profundas donde al sacar el aire se deja que el cuerpo se relaje y la mente se serene. Pausa.

- Se vuelve a hacer otra inspiración profunda y se suelta todo aquello que nos priva de paz. Pausa.

- Una tercera inspiración profunda que ayuda a centrar la atención en nuestros pies. Se recorren con la imaginación y se percibe la conexión que existe entre nosotros y la Tierra en que nos apoyamos. Pausa.

- Se imagina cómo a través de nuestros pies surgen unas raíces energéticas que ahondan en la tierra y nos conectan directamente con su núcleo, con el corazón de la Madre Tierra. Pausa.

- Sentimos cómo la Madre Tierra nos abraza y nos protege como una madre a su hijo, aportándonos seguridad, firmeza, confianza, fuerza. Pausa.

Revista Cultura \& Religión Vol. XIII, 2019 № 2 (julio-diciembre)

Cómo citar este artículo: Pastor-Talboom, S. (2019). "La red y los círculos de Ánima. Orígenes, doctrina y sistematización de sus fuentes”. Revista Cultura \& Religión.13(2). pp. 30-51. 
- Dejamos que absorba de nosotros los miedos, las dudas, las inseguridades, mientras nos equilibra y nos serena. Permitimos que su maravillosa energía ascienda a través de nuestros pies y piernas hasta nuestro corazón. Pausa.

- Ahora ponemos nuestra atención en la corona de nuestra cabeza, en nuestro séptimo chacra y sentimos como existe una poderosa conexión con la Fuente, con el Universo a través de un potente tubo de luz blanca. Pausa.

- Estamos directamente conectados con la fuente, y nos aporta sabiduría, amor, claridad y confianza. Pausa.

- Notamos como esta intensa luz blanca desciende a través de nuestra cabeza hasta nuestro corazón, donde se UNE con la energía de la Madre Tierra. Pausa.

- Al fusionarse se crea una gran explosión de luz. La unión del cielo y la tierra manifestándose a través de nosotros, de nuestro corazón. Pausa.

- Esa poderosa luz de Amor abre nuestro corazón, y lo expandimos. Dejamos que se fusione con las energías de los corazones de los demás participantes, formando un Círculo de unión de corazones.

Terminada la meditación de apertura, se pueden realizar las invocaciones que más resuenen ${ }^{4}$ a los asistentes. Por ejemplo: pedir permiso a los guardianes del lugar o seres en tránsito anclados en el lugar donde nos encontramos, para poder realizar el círculo, ya que el respeto a los que viven allí es fundamental; solicitar la presencia de los elementales del aire, agua, tierra y fuego; pedir la presencia y ayuda de los guías espirituales y seres de luz que acompañan a los asistentes, para que formen un círculo alrededor del que se ha creado; conectar con la energía de nuestra Divinidad para hacernos presentes e irradiar sabiduría a través del amor; solicitar la presencia del arcángel Miguel, para que abra un portal interdimensional y nos guíe y proteja con su luz y sabiduría. A continuación, se dice en voz alta: Este Círculo está abierto. Se pueden soltar las manos y colocarse en la postura que sea más cómoda.

El desarrollo del círculo puede ser de diversos tipos. Se puede tratar de un círculo abierto. En este caso simplemente se facilita el paso a los seres en tránsito que deseen pasar a la luz y contactar con aquellos que así lo expresen a través de algún o algunos de los participantes. También se puede realizar un círculo para casos en concreto solicitados por los propios asistentes (normalmente para sus conocidos o familiares) o incluso para casos a distancia. En este caso se llama a estos familiares una sola vez, y sólo una, y nunca se les invoca (el espiritismo de la ouija es rechazado por creer que pertenece a la Vieja Era). Pero lo más frecuente es que se trate de un círculo mixto.

\footnotetext{
${ }^{4}$ Es frecuente la alusión a la tríada materia/energía/vibración-frecuencia. Por tanto, las personas pueden tener energías elevadas que sintonizan con determinadas frecuencias, o arrastrar energías densas, bajas que resuenan o vibran con otro tipo de frecuencias.
}

Revista Cultura \& Religión Vol. XIII, 2019 № 2 (julio-diciembre)

Cómo citar este artículo: Pastor-Talboom, S. (2019). "La red y los círculos de Ánima. Orígenes, doctrina y sistematización de sus fuentes”. Revista Cultura \& Religión.13(2). pp. 30-51. 
Al final del círculo se dejan unos minutos para proyectar al centro del círculo, donde las energías de la Fuente fluyen directamente, a los seres queridos que están enfermos o a lugares con energías densas, pero siempre recitando la frase Si está en el camino de esa persona, o le corresponde a esa situación o lugar, ya que no se sabe si la situación que está viviendo esa persona la ha elegido su misma alma para aprender y evolucionar. Tras ello se pregunta a los asistentes si todos están bien para proceder a cerrar el círculo. Si se tienen algunas sensaciones de contacto con seres, se les dice a los asistentes que las proyecten al centro del círculo para desprenderse de ellas o bien se les dice a esos seres que se vayan al siguiente círculo de luz (en la dimensión astral el tiempo es distinto al nuestro y por ello pueden esperar al siguiente círculo). Se recita en voz alta Todos los seres en tránsito que estén en este momento en el Círculo que se dirijan al lugar que por ley divina les corresponde.

Se finaliza con una pequeña meditación de cierre. Para ello se vuelve a coger de las manos y se cierran los ojos, se realiza una inspiración profunda, y nos hacemos conscientes de la intensa y poderosa energía de amor y luz que hay en el círculo. Se dan las gracias a los seres de luz, al arcángel Miguel, a la madre tierra y a nuestro propio ser. En voz alta se dice Este círculo está cerrado o bien Este portal queda cerrado al astral.

\section{Sistematización de sus fuentes}

La ideología de Agartam no es institucional. No se trata de una asociación que funcione como un dispositivo que ejerce un poder de normalización y disciplina, del tipo foucaultiano (Foucault, 2012). A pesar de contar con la ECA (Equipo de Coordinación de Agartam) formada por cada uno de los coordinadores de sus 15 Redes, no hay estatutos ni reglas escritas. Hay confianza. Se trata de un ideario elaborado y reelaborado por personas individuales que reclaman, en consonancia con el individualismo occidental (Bauman, 2006; Giddens, 1995; Dumont, 1987), el derecho a vivir y a manifestar su "yo soy", su propia divinidad, el "ser de luz" que cada uno es. El individualismo se reclama para la defensa de su autonomía de acción y de libre albedrío, ya que no hay jerarquía institucional, y se supera a su vez en defensa de la unidad, una unión con la dimensión espiritual más elevada, más amorosa, la Conciencia Crística.

En un intento de sistematización de las fuentes de esta asociación, se puede apreciar un absoluto sincretismo de varias corrientes religiosas y espirituales que se pasan a describir a continuación y que son a su vez, seguramente, sincréticas:

\subsection{New Age}

El nombre de New Age o Nueva Era hace alusión a la entrada de la Tierra en la Era de acuario. Como resume Díaz Brenis (2002),

Revista Cultura \& Religión Vol. XIII, 2019 № 2 (julio-diciembre)

Cómo citar este artículo: Pastor-Talboom, S. (2019). "La red y los círculos de Ánima. Orígenes, doctrina y sistematización de sus fuentes”. Revista Cultura \& Religión.13(2). pp. 30-51. 
El pertenecer a la Nueva Era asume una connotación astrológica, debido a que se inserta en la transición de la era de Piscis a la era de Acuario, lo cual nos lleva a la idea esotérica del "gran año cósmico", también denominado "año platónico". Con este nombre se pretende indicar el tiempo que emplea el eje de la tierra en recorrer todas las constelaciones del cielo, es decir, los doce signos del Zodiaco, de los cuales cada uno posee una duración aproximada de 2.100 años, los cuales dividen al año cósmico en 12 meses cósmicos. (Díaz Brenis, 2002, p. 46)

Efectivamente las alusiones constantes de la asociación Agartam a la Nueva Era tienen connotaciones astrológicas. Carol Mateos explica que esta nueva era refiere a una época de luz después de la noche galáctica, describiendo la órbita de Ors alrededor de Alción. La fecha de 21/12/2012 no se considera

El fin del mundo si no el fin paulatino de un ciclo galáctico en el que la humanidad sufrió una caída de conciencia o desconexión. Durante 13.000 años aproximadamente, han influido un tipo de energías más densas para que el ser humano evolucionara experimentando a través de ellas [...] Ahora estamos entrando en un nuevo ciclo en el que estamos recuperando la conexión. (Mateos, 2016, s.p.)

Además no son infrecuentes las referencias a Sirio, el sol central del universo, y a sus habitantes. Y a los maestros ascendidos, que provienen de las siete Pléyades y sus siete rayos, cada uno de un color. Uno de estos maestros ascendidos es Ashtar Sheran, el comandante extraterrestre para sus seguidores. Está a cargo de miles de naves que custodian la Tierra ante eventuales peligros.

Pero la connotación astrológica se desarrolla y da lugar a un movimiento espiritual occidental mucho más complejo y holista. Es posmoderno, esotérico y milenarista (Morris, 2009), que ha sido estudiado en profundidad por Heelas (1996) y Hanegraaff (1996). Pensando en sus características, uno de los primeros indicios que hicieron pensar en esta asociación como otro de los movimientos pertenecientes a la New Age o Nueva Era fue la ausencia de jerarquía, es decir, la creencia en que cada persona tiene la chispa divina y que no tiene porqué depender de un superior para establecer qué creencia es 'dogmática' o no. La relación entre religión neoeriana y la "autonomía" como macromovimiento sociocultural postsesentista es clave (Carozzi, 1999). O como dice Heelas (1996), la sacralización del self: la verdad es resultado simplemente de la experiencia y la epistemología subjetiva (tal como nos transmitía un coordinador de Agartam y mediador en los círculos de ánima, "a mí me da igual si los demás creen o no, yo lo he experimentado").

En segundo lugar y en relación con el punto anterior, la organización de Agartam en redes. El logo-símbolo de la asociación es reticular (nueve puntos unidos entre sí formando un rombo y un aspa) y la asociación se define por una red de redes. Efectivamente, la formación de esta asociación y de los círculos no es piramidal, en consonancia con la ausencia de jerarquía a la que hemos aludido. Aunque exista como tal la figura de la 'Fundadora' y de los coordinadores de Agartam, tanto de países como de cada una de las redes, la creencia en la unidad hace más visible la aportación equitativa de cada uno de sus

Revista Cultura \& Religión Vol. XIII, 2019 Nº 2 (julio-diciembre)

Cómo citar este artículo: Pastor-Talboom, S. (2019). "La red y los círculos de Ánima. Orígenes, doctrina y sistematización de sus fuentes”. Revista Cultura \& Religión.13(2). pp. 30-51. 
componentes, incluidos los asistentes anónimos de los círculos. La conceptualización del mundo por la Nueva Era como una Gran Red se explica, según Contepomi (2007), por varias razones. Una de ellas sería la influencia de las ciencias naturales y dentro de ellas de la Teoría General de Sistemas cuyo concepto central es el de la totalidad integrada y la noción de sistema como un conjunto de elementos interrelacionados entre sí por medio de una red. El cambio en una parte afecta al resto. La siguiente tiene que ver con tradiciones filosóficas y religiosas orientales que "contemplan el universo en su conjunto como un gran sistema holístico, como una unidad indivisible y dinámica cuyos elementos están estrechamente vinculados. Desde esta perspectiva, todo está unido entre sí, básicamente, por una red" (Contepomi, 2007, p. 104). La tercera está relacionada con la era actual globalizadora y con el desarrollo de las tecnologías de la información y comunicación, ambas conducentes a la unión de los seres humanos.

Con respecto a los préstamos culturales y fuentes intelectuales de la Nueva Era, es interesante la recopilación que realiza Escandell (2009) de la obra de Sánchez (1997). Muchos de ellos se han podido apreciar en la asociación objeto de estudio: el subjetivismo kantiano (en el yo soy), el monismo ontológico (la creencia en una única entidad ontológica, la unidad), la psicología transpersonal de Ken Wilber (se pueden alcanzar niveles superiores de conciencia entrando en contacto con la propia divinidad interior), la creencia en la reencarnación (un informante había podido ver una antigua vida suya como guerrero de la Atlántida), la relajación y meditación hinduistas y budistas, el feminismo (se habla de la Diosa), los movimientos ecologistas (se pretende una unión del hombre con la naturaleza e, incluso, con la realidad cósmica, lo que permite entrever una isla holista, en el sentido dumontiano, en una ideología predominantemente individualista) y la inmanentización de Dios (entendida como que todos podemos ser, y de hecho somos, divinos).

Asimismo es muy común la referencia a Dios como la "fuente", entendida en términos impersonales, como una energía o fuerza vital. Además se cree en la existencia de toda una miríada de seres espirituales como deidades planetarias, ángeles, espíritus, entidades desencarnadas, presencias experimentadas de manera subjetiva, el Cristo cósmico... (Morris, 2009), de los cuales todos deberíamos poder canalizar sus mensajes ${ }^{5}$.

\subsection{Neopaganismo}

Siguiendo a Morris (2009), el neopaganismo supone un resurgimiento del paganismo precristiano y se da en sociedades occidentales. Los elementos de este movimiento 'revitalizador' son los siguientes (Morris, 2009) y efectivamente Agartam los evoca:

\footnotetext{
${ }^{5}$ La fundadora de Agartam ha escrito y publicado varios libros canalizados (Yo Jesús de Nazaret, María la de Magdala, Cartas Arcangélicas, La Vida Oculta de Jesús, entre otros), y la realización continua de cursos para 'aprender a canalizar' es una de sus fuentes de ingresos.
}

Revista Cultura \& Religión Vol. XIII, 2019 № 2 (julio-diciembre)

Cómo citar este artículo: Pastor-Talboom, S. (2019). "La red y los círculos de Ánima. Orígenes, doctrina y sistematización de sus fuentes”. Revista Cultura \& Religión.13(2). pp. 30-51. 
- El politeísmo radical. Agartam reconoce una pluralidad de seres espirituales entre los que se encuentra la Gran diosa Madre.

- La perspectiva ecológica. Agartam hace hincapié en la ecología y el medioambiente. Busca la elevación de la conciencia del planeta Tierra y gusta de crear eventos y rituales en la naturaleza abierta de montañas, como la de Montserrat (Cataluña, España), a las que se les presupone una gran vibración energética y en las que se puede ver el abrazo a árboles. En relación por ejemplo con los Círculos de Ánima y llegado el buen tiempo también se invitó a los asistentes, a través de un mensaje en el grupo de la red social Whatsapp, al círculo del 15 de junio de 2018 para realizarlo en la montaña de Esporlas (Mallorca, España). Había que llevar un cojín para sentarse cómodamente sobre la tierra, buscar una conexión directa con la madre tierra y con los seres de luz de la naturaleza y llevar ofrendas de origen natural como frutos secos, fruta pequeña entera o flores silvestres.

- El feminismo ${ }^{6}$. La gran mayoría de asistentes a los círculos, alrededor de un $80 \mathrm{o}$ $90 \%$, son mujeres. Algunas de ellas están relacionadas con el movimiento Womb Blessing o Bendición del Útero ${ }^{7}$ y con el concepto Sagrado Femenino, es decir, la creencia en las diferentes etapas del ciclo menstrual como fases de diversas cargas energéticas, en la siembra de la sangre como un retorno de la sangre menstrual a la madre tierra y en el orgullo de ser mujer.

- La política descentralizada. Agartam es individualista y autónoma.

- La celebración del ritual. En los Círculos de Ánima de Agartam el ritual permite la comunicación con los espíritus.

- La importancia de la experiencia espiritual. La canalización y la 'imaginación' son los canales predilectos.

- El esoterismo. Efectivamente el trabajo de campo permite afirmar que Agartam busca el autoconocimiento, la armonía interna y la autorrealización: el 'Yo'. Los rituales implican un cambio de conciencia.

Y si cinco son los subtipos del neopaganimo, la wicca, la brujería feminista, la tradición nórdica, el druidismo y el esoterismo occidental (Morris, 2009), son estos dos últimos los más patentes.

Respecto al druidismo destacan las alusiones de Alicia Sánchez (Sánchez Montalbán \& Polo, 2016) a los grandes monumentos líticos circulares de Stonehenge y Avebury en el Reino Unido. En el momento en que visita junto con su pareja el monumento lítico de

\footnotetext{
${ }^{6}$ Para una derivación política del feminismo en combinación con la ecología del punto anterior véase el ecofeminismo (Setright, 2014)

${ }^{7}$ La Bendición del Útero fue creada por la escritora y profesora espiritual Miranda Gray. Se trata de un movimiento que facilita talleres sobre la naturaleza cíclica y menstrual de las mujeres, su espiritualidad y sus energías, con el fin de acentuar sus dones creativos, sexuales y espirituales. Para más información puede visitarse la página oficial Womb Blessing (Gray, 2012).
}

Revista Cultura \& Religión Vol. XIII, 2019 № 2 (julio-diciembre)

Cómo citar este artículo: Pastor-Talboom, S. (2019). "La red y los círculos de Ánima. Orígenes, doctrina y sistematización de sus fuentes”. Revista Cultura \& Religión.13(2). pp. 30-51. 
Avebury, crea, a sugerencia de sus guías y para ayudar a las almas en tránsito del lugar, un tubo de luz desde la Fuente hasta el centro de la tierra y sus guías lo unen a la ciudad de Ávalon. Es interesante la conceptualización de Ávalon como "una puerta etérica a un espacio de infinita luz donde hay muchos seres dispuestos a ayudar en el proceso de comprensión de las almas que no logran superar su estancamiento" (Sánchez Montalbán \& Polo, 2016, p. 92). Para Alicia (2016) sería el purgatorio cristiano y se encuentra en la cuarta dimensión, en un espacio creado entre la Tierra y la Luz. Para acceder a Ávalon es imprescindible que esas almas pidan ayuda (un ejemplo del respeto en esta asociación al libre albedrío) y es sugerido por la fundadora como un recurso más para la ayuda a los seres en tránsito en los círculos:

Si te encuentras con un alma en tránsito, cuya conciencia pide ayuda, pero le cuesta comprender, conecta el tubo de luz que has creado frente a ti con el que hay en Avebury. Luego solicita que se abra para ella la puerta de Ávalon. A continuación, siente, percibe y maravíllate. (Sánchez Montalbán \& Polo, 2016, p. 92)

Por otro lado se relaciona con el esoterismo occidental porque Agartam cree en la existencia de varios planos, a modo de un complejo puzle espiritual. No solo hay un plano material de existencia sino el plano de la mente, del espíritu y del reino astral. Se da mucha importancia a los seres celestiales: el sol, la luna, los planetas y las más distantes estrellas. También al interior (la divinidad o yo superior está dentro de la persona) y a las numerosas fuerzas espirituales como los espíritus guías, ángeles y arcángeles. Finalmente es relevante la creencia en la reencarnación y en vidas pasadas a las que se puede acceder a través de terapias de regresión (Mateos, 2016).

Especialmente importante es la práctica, citada en Morris (2009), de la llamada por Sutcliffe (1996) imaginación activa o esotérica. Se trata del desarrollo de una "conciencia analógica" y una "visualización" (Luhrmann, 1989, p. 207) de los espíritus a través de la "experimentación de vívidas imágenes mentales interpretadas como auténticos seres espirituales" (Morris, 2009, p. 372).

\subsection{Teosofía ${ }^{8}$}

Es propio de la teosofía el fomento del autodesarrollo personal para el hallazgo de la 'auténtica' verdad, ya que las diversas religiones son parciales y están manipuladas, y la creencia de que el universo en su totalidad constituye una Unidad y la separación entre los seres es pura apariencia (Escandell, 2009). Ambas presunciones son frecuentes en el discurso de Alicia Sánchez (Agartam, 2009).

\footnotetext{
${ }^{8}$ La Sociedad Teosófica fue creada por Helena Petrovna Blavatsky, de origen ruso, en el siglo XIX. Según Madame Blavatsky, como se la conocía, esta Sociedad tenía por objeto recoger y difundir el conocimiento de las leyes que gobiernan el universo, y sus propósitos eran, primero, formar una Fraternidad Universal de la Humanidad y, segundo, fomentar el estudio comparativo de la religión, la ciencia y la filosofía (Blavatsky, 1962).
}

Revista Cultura \& Religión Vol. XIII, 2019 № 2 (julio-diciembre)

Cómo citar este artículo: Pastor-Talboom, S. (2019). "La red y los círculos de Ánima. Orígenes, doctrina y sistematización de sus fuentes”. Revista Cultura \& Religión.13(2). pp. 30-51. 
Además, en la asociación objeto de estudio se han podido apreciar rasgos de distintas religiones como la cristiana, en la figura de Cristo y la de los ángeles y arcángeles por ejemplo (Mateos, 2016); la budista, ya que una de las redes de Agartam es la Red de Reiki, entendido el reiki como una imposición de manos terapéutica (Agartam, 2009); la hinduista, concretamente en la alusión a los siete chacras y su utilización en las meditaciones de los círculos de ánima en los que ha habido observación participante, así como la utilización de los conceptos de karma y dharma (Mateos, 2016), y el espiritismo. En este último caso con citaciones, en el Curso de Ánima realizado por la investigadora, de médiums como el famoso Chico Xavier y la película Nosso Lar, que se basa en la vida de uno de sus contactados.

Por otro lado, se toma prestado de las doctrinas orientalistas la creencia sobre niveles de ascensión, concretamente en la figura de los maestros ascendidos. Se refieren con este término a seres que fueron anteriormente en vidas pasadas personas ordinarias y que, tras sucesivas reencarnaciones y procesos iniciáticos y de elevación espiritual, han ascendido todas las dimensiones. Una vez ascendidos quedan libres del ciclo de reencarnación, se encuentran en la sexta dimensión y se convierten en portadores de enseñanzas para los seres humanos (Mateos, 2016). Pues bien, los maestros ascendidos son, entre otros como los arcángeles Metatrón y Miguel, guías espirituales de Agartam, según sus coordinadores (Agartam, 2009), y tienen nombres propios: Sananda (unas de cuyas encarnaciones habría sido Jesús o Buda), Sanat Kumara, El Morya, Hilarión y Ashtar Sheran?.

\subsection{Física Cuántica ${ }^{10}$}

No hay que olvidar la frase de Marilyn Ferguson: "La conciencia es más vasta y profunda y la intención es más poderosa de lo que nadie creía. Claramente los seres humanos no han comenzado a explotar aún su potencial de cambio" (Ferguson, 1998, p.170, cursiva añadida). Efectivamente, dentro del material (inédito) que facilita Carol Mateos en los cursos de Ánima aparece un apartado dedicado a la fuerza de la atención y la intención. En él también se nombra a la 'física cuántica' y se hace para resaltar las infinitas posibilidades a las que podemos dirigirnos en esta realidad siendo nuestra atención e intención las que decidirán el rumbo. Es decir, la evocación de la física cuántica se realiza básicamente a través del uso del término intención como la capacidad de dirigir nuestra atención o energía hacia

\footnotetext{
${ }^{9}$ Comunicación personal, 21 de enero, 2017.

${ }^{10}$ De la visión que tienen de lo que es la física cuántica. En este apartado interesan las alusiones que este colectivo espiritual hace a la "física cuántica", es decir, las apropiaciones culturales emic de esta disciplina científica. No se trata por tanto de una adscripción etic de la autora. Aun así se ha mantenido el término, utilizado tanto por los coordinadores de Agartam como por los asistentes a los círculos de ánima, con el fin de poner de relieve esta apropiación.
}

Revista Cultura \& Religión Vol. XIII, 2019 № 2 (julio-diciembre)

Cómo citar este artículo: Pastor-Talboom, S. (2019). "La red y los círculos de Ánima. Orígenes, doctrina y sistematización de sus fuentes”. Revista Cultura \& Religión.13(2). pp. 30-51. 
un punto o estado concreto y deseado. En el desarrollo del ritual de un Círculo de Ánima el poder de la intención se utiliza para elevar la vibración de uno mismo o de los asistentes a pesar del contacto con seres densos o de baja vibración.

Por su parte, Alicia Sánchez (Sánchez Montalbán \& Polo, 2016) nombra nueve leyes que regirían nuestra realidad: la ley del uno, la ley de la causa y efecto, la ley de la mirada creadora, la ley de la atracción, la ley del tiempo y el espacio, la ley del equilibrio, la ley del libre albedrío, la ley del respeto y la ley de la sincronicidad. Pues bien, sería la tercera, la llamada ley de la mirada creadora la que trae ecos de la física cuántica: cada vez que fijamos la atención en algo le damos fuerza a nuestra realidad. Asimismo ha canalizado a través de los guías de Agartam una serie de herramientas cuánticas que se decriben brevemente: el baño de luz ultravioleta (luz violeta que desciende desde la fuente disolviendo los lazos energéticos, transformando en luz las emociones y elevando la vibración), la esfera de luz azul (luz del alma que tras cerrar los ojos y concentrarse en el arcángel Miguel se expande hasta abarcar a toda la persona y le ayuda), la estrella de cierre (el dibujo en el aire con la mano derecha de un círculo, una cruz y unas aspas concéntricas que sirve para cerrar nuestra energía al astral y así poder evitar intrusiones no deseadas) y el baño de luz estréllica (tubo de luz desde la fuente hasta el centro de la tierra que imaginamos nos rodea y que nos permite protegernos). Se trata de recursos para las almas en tránsito a las que les cuesta especialmente recordar su luz y que por tanto, al tener bajas vibraciones, pueden molestar. Y se llaman cuánticas "porque su efecto es inmediato, resuelven al instante, cuando se hace necesario" (Sánchez Montalbán \& Polo, 2016, p.196).

Acaba este apartado con la alusión y puesta en común por parte de los asistentes a uno de los Círculos de Ánima en Mallorca, España, de la Teoría de Cuerdas. A pesar de su complejidad $^{11}$, esta teoría defiende que los 'puntos' de materia más pequeños que los átomos y los quarks son en realidad estados vibratorios de un filamento o cuerda. El problema sería de escala: lo que aparentemente es un punto no dimensional al acercarnos lo suficiente es vibración, movimiento. Estas vibraciones se darían en diez u once (dependiendo de las diversas subteorías) dimensiones, incluyendo en ella las cuatro ordinarias. En un intento de unión de ciencia y espiritualidad se argumentó que cuando ellos hablaban de vibración o resonancia en realidad estaban apoyándose en la 'ciencia': todos, en realidad, somos vibración y ésta se activa cuando conectamos con la misma frecuencia. Esto explicaría además la importancia que tiene dentro de Agartam la Red de Sonido. De hecho, tal como se ha podido apreciar durante la investigación mediante observación participante, no es infrecuente la armonización de energías durante el ritual de los círculos mediante diapasones, cuencos tibetanos y cantos espirituales gregorianos, como por ejemplo el Canto de la Sibila.

${ }^{11}$ Para una visión sencilla de la cuestión véase Instituto de Física Teórica (2016).

Revista Cultura \& Religión Vol. XIII, 2019 № 2 (julio-diciembre)

Cómo citar este artículo: Pastor-Talboom, S. (2019). "La red y los círculos de Ánima. Orígenes, doctrina y sistematización de sus fuentes”. Revista Cultura \& Religión.13(2). pp. 30-51. 


\subsection{Numerología y Geometría Sagrada}

La numerología tiene como uno de sus referentes a Nikola Tesla y su preferencia por los números tres, seis y nueve, siendo especialmente relevante el nueve (Necesitas Saberlo, 2017). Se considera al nueve un portal interdimensional que permite comunicar realidades diferentes como son la tercera y la cuarta dimensión. Un ejemplo aducido por sus defensores es la duración de la gestación humana, entendido el nacimiento de un bebé como el ingreso desde un plano no físico al plano físico. La gestación dura nueve meses, nueve, o 36 semanas, tres+seis=nueve, o 252 días, dos+cinco+dos=nueve. Otro ejemplo de la magnificencia de este número es que es la suma de cualquier ángulo de un círculo que, como se verá a continuación, es la forma primigenia y perfecta para la geometría sagrada. Ya sea $360^{\circ}, 180^{\circ}$, $90^{\circ}, 45^{\circ}, 22^{\prime} 5^{\circ}, 11^{\prime} 25^{\circ} \ldots$, todos los ángulos suman nueve. Se supone que el nueve está relacionado con el campo energético del éter, la quintaesencia aristotélica tras la tierra, agua, fuego y aire, donde todo es energía, frecuencia y vibración, de manera que su vibración superior, de la cuarta dimensión, incluye a todos los demás. Constituiría la graduación del aprendizaje. El seis por su parte sería considerado una vibración inferior y relativa a la realidad física de la tercera dimensión, la nuestra. Desde el punto de vista de la numerología, modificando los números modificamos la vibración de nuestras vidas, y modificando la vibración modificamos nuestra realidad.

En el estudio de Agartam y dentro de ella de la Red de Ánima de la que los Círculos forman parte, se ha podido apreciar en varias ocasiones las alusiones al nueve: nueve son las leyes que rigen nuestra dimensión; nueve es el número que los guías le dicen a Alicia Sánchez que está relacionado con el Proyecto Agartam; nueve son los puntos del logo de Agartam y nueve sus valores; la fundadora de Agartam considera una señal de sus guías que la primera meditación de luna llena llevada a cabo por la asociación se realizara en la playa delante de la casa $\mathrm{n}^{\circ} 18$, uno+ocho=nueve, y que fueran asimismo 18 personas las asistentes; son 72 , siete + dos $=$ nueve, las horas que tiene un alma tras fallecer para irse a la $L u z$ antes de olvidar el camino a la misma.

La Geometría Sagrada, de cierta reminiscencia masónica, es, para sus seguidores y defensores, de entre los cuales podemos destacar a Drunvalo Melchizedek, una parte de la geometría que debe su nombre a su carácter fundamental como código de información para entender el nacimiento del Universo/Vida. Según Melchizedek (Sotomayor, 2017), este empieza con un círculo y de ahí se van superponiendo varios siguiendo una sencilla regla, aplicar lo único conocido. La figura resultante es la llamada Flor de la Vida, que se asemeja al patrón de la multiplicación celular y que está formada por 19 círculos, y la figura siguiente, el Fruto de la Vida, formada por 13 círculos. Si a estos 13 círculos, componente femenino, les añadimos líneas rectas, componente masculino, que atraviesan todos sus centros obtenemos el llamado Cubo de Metatrón. Esta figura se considera fundamental porque en

Revista Cultura \& Religión Vol. XIII, 2019 № 2 (julio-diciembre)

Cómo citar este artículo: Pastor-Talboom, S. (2019). "La red y los círculos de Ánima. Orígenes, doctrina y sistematización de sus fuentes”. Revista Cultura \& Religión.13(2). pp. 30-51. 
ella están contenidos los cinco sólidos platónicos: cinco volúmenes que comparten las mismas características, que son un solo tamaño de cara, un solo tamaño de arista, una sola amplitud de ángulo y que todas sus puntas caben en un círculo, y que son el cubo, el tetraedro, el octaedro, el icosaedro y el dodecaedro pentagonal (Sotomayor, 2017). La referencia al arcángel Metatrón es debida a que se piensa que es la representación de su alma perfecta y una protección frente a los seres de baja vibración.

En la Red de Ánima es frecuente la alusión al "círculo" como la representación de la Unidad. También se conoció por ellos la existencia del cubo de Metatrón. Según la fundadora de la asociación es este arcángel uno de los principales seres de luz que guió la iniciativa de poner en marcha Agartam (Agartam, 2009).

\section{Conclusiones}

Agartam y sus redes, incluida la del objeto de estudio, han tenido un origen ciertamente reciente. No obstante, su asentamiento y difusión por diferentes zonas de la geografía española, y contemporáneamente por diferentes países de Iberoamérica, es sorprendente. Las incursiones en estados europeos, del sur en cualquier caso, como Francia e Italia, así como en EEUU, hasta el momento sólo Miami, son recientes o esporádicos, hasta la fecha, y está por ver su evolución posterior. Es difícil el cálculo de sus integrantes y practicantes reales ya que en la página oficial de la asociación no aparecen todas las convocatorias. El motivo aducido es que no todos sus organizadores quieren manifestarlo públicamente y de hecho, de aquellos que lo hacen, no siempre presentan toda la información, para evitar el intrusismo, y prefieren el contacto privado, normalmente por correo o mensajería telefónica. En cualquier caso, a veces las cifras hablan por sí solas. El vídeo de Carol Mateos, accesible públicamente desde You Tube, y titulado "La vida después de la muerte y cómo ayudar a las almas a ir hacia la luz" "12, tiene más de 364.000 visualizaciones tras cuatro años de su publicación. Dedicada en la actualidad más hacia la divulgación que a la práctica de Círculos de Ánima, no parece por ahora que, por parte de Carol Mateos, vaya a haber una duplicidad de redes de ánima más allá de Agartam. Pero sí se ha podido tener ecos de lo que es un Círculo en el discurso de las escritoras y divulgadoras mexicanas Jocelyn Arellano y Carmen de Sayve (en su caso también médium). Precisamente la posible aparición de asociaciones paralelas a la Red de Ánima, y sus Círculos de Ánima, sería una interesante propuesta de investigaciones futuras.

Por otro lado, el sincretismo ideológico de Agartam, como se ha intentado mostrar, es complejo y sobre abundante. El navegar por sus páginas puede ser para un lego en el tema realmente abrumador. Parece inverosímil, y también apasionante, que pueda haber tanta información disponible para sus seguidores, y que exista de forma paralela a la 'ciencia'. Una

\footnotetext{
${ }^{12}$ Véase Mateos, 2014
}

Revista Cultura \& Religión Vol. XIII, 2019 Nº 2 (julio-diciembre)

Cómo citar este artículo: Pastor-Talboom, S. (2019). "La red y los círculos de Ánima. Orígenes, doctrina y sistematización de sus fuentes”. Revista Cultura \& Religión.13(2). pp. 30-51. 
vez más la antropología recoge el testigo y hace posible la descripción cultural de una cosmovisión emic del universo para acercarla al ámbito y discurso académicos.

\section{Referencias}

Agartam. (2009). Agartam: Colaboradores de Agartam. Consultado en 10 de julio de 2018: http://www.agartam.com/

Agartam. (2018). Revista Agartam: Agartam. Consultado en 30 de junio de 2018: http://www.agartam.com/

Bauman, Z. (2006). Vida líquida. Barcelona: Paidós Ibérica.

Blavatsky, H. P. (1962). La doctrina secreta (Vol. I). Buenos Aires: Kier.

Carozzi, M. J. (1999). "La autonomía como religión: la nueva era". Alteridades, 18(1), pp. de 19 a 38, visitado el 4 de abril de 2018. (http://alteridades.izt.uam.mx/index.php/Alte/article/view/439)

Contepomi, M. d. R. (2007). "La gran red: una era nueva entre la ciencia y el mito". Avá: Revista de Antropología, 10(1), pp. de 97 a 118, visitado el 5 de mayo de 2018. (http://argos.fhycs.unam.edu.ar/handle/123456789/358)

Di Nola, A. (2007). La muerte derrotada. Antropología de la muerte y el duelo. Barcelona: Belacqva.

Díaz Brenis, E. (2002). "Nueva Era: una religión para la polis posmoderna". Boletín Oficial del INAH. Antropología, 68(1), pp. de 44 a 49, visitado el 5 de junio de 2018. (https://revistas.inah.gob.mx/index.php/antropologia/article/view/4969)

Dumont, L. (1970). Homo Hierarchicus. Ensayo sobre el sistema de castas. Madrid: Aguilar.

Dumont, L. (1987). Ensayos sobre el individualismo. Una perspectiva antropológica sobre la ideología moderna. Madrid: Alianza Editorial.

Dumont, L. (1999). Homo Aequalis. Génesis y apogeo de la ideología económica. Barcelona: Taurus Ediciones.

Escandell, J. J. (2009). "La Nueva Era de Acuario, una Nueva Humanidad: La auténtica fachada de La Conspiración de Acuario, de Marilyn Ferguson”. Revista Arbil, 89(1), pp. de 1 a 37, visitado el 7 de julio de 2018. (http://www.arbil.org/89nera.htm)

Ferguson, M. (1998). La conspiración de Acuario. Transformaciones personales y sociales de este fin de siglo. Barcelona: Kairós.

Foucault, M. (2012). Vigilar y Castigar. Madrid: Siglo Veintiuno Editores.

Fuller, R. C. (2001). Spiritual, but no religious: understanding unchurched america. Oxford: Oxford University Press.

García Hernández, A. (2008). "Re-pensar la muerte: Hacia un entendimiento de la antropología de la muerte en el marco de la ciencia". Revista Cultura \& Religión. Vol. 2(1).pp. 43-61.

Giddens, A. (1995). Modernidad e identidad del yo: el yo y la sociedad en la época contemporánea. Barcelona: Península.

Revista Cultura \& Religión Vol. XIII, 2019 № 2 (julio-diciembre)

Cómo citar este artículo: Pastor-Talboom, S. (2019). "La red y los círculos de Ánima. Orígenes, doctrina y

sistematización de sus fuentes”. Revista Cultura \& Religión.13(2). pp. 30-51. 
Gray, M. (2012). The Worldwide Womb Blessing. Recuperado el 27 de Noviembre de 2018 de http://www.wombblessing.com/

Hanegraaff, W. (1996). New Age Religion and Western Culture: Esotericism in the Mirror of Secular Thought. Leiden : Brill.

Heelas, P. (1996). The New Age Movement. The Celebration of the Self and the Sacralization of Modernity. Oxford: Blackwell Publishers.

Heelas, P. \& Woodhead, L. (2005). The Spiritual Revolution. Why Religion is Giving Way to Spirituality. Oxford: Blackwell.

Instituto de Física Teórica. (2016). La teoría de Cuerdas en 7 minutos [Vídeo]. Recuperado el 30 de junio de 2018 de https://www.youtube.com/watch?v=yd1jx1DkXb4

Koss-Chioino, J. (2010). "Introduction to 'Do Spirits Exist? Ways to Know"'. Anthropology and Humanism. 35(2). pp. 131-141.

Kübler-Ross, E. (2011). La muerte: un amanecer. Barcelona: Luciérnaga.

Kübler-Ross, E. (2012). Sobre la muerte y los moribundos. Barcelona: Debols!1lo

López Novo, J. P. (2012). "Espiritual pero no religiosa: la cultura de la transformación personal". 'Ilu. Revista de Ciencias de las Religiones. 17(1). pp. 77-99.

López-Pavillard, S. \& Blanes, R. (2017). "Etnografiando prácticas espirituales: sentido y compromiso frente a la utopía”. En XIV Congreso de Antropología, València 58/9/2017: Antropologías en Transformación: Sentidos, Compromisos y Utopías (pp. 1084-1096). T. Vicente Rabanaque, M. J. García Hernandorena \& T. Vizcaíno Estevan (Compiladores). València. Universitat de València.

Luhrmann, T. M. (1989). Persuasions of the Witch's Craft. Cambridge: MA: Harvard University Press.

Luhrmann, T. M. (2018). "The real ontological challenge". HAU: Journal of Ethnographic Theory. 8(1/2). pp. 79-82.

Mateos, C. (2014). La vida después de la muerte y cómo ayudar a las almas a ir hacia la luz [Vídeo]. Recuperado el 2 de Diciembre de 2018 de https://www.youtube.com/watch?v=Qk8KLZoA8YY

Mateos, C. (2016). La Luz de la Conciencia [Blog]. Recuperado el 14 de junio de 2018 de https://laluzdelaconciencia.wordpress.com/carol-mateos/

Morris, B. (2009). Religión y antropología. Una introducción crítica . Madrid: Akal.

Necesitas Saberlo. (2017). ¿Por qué NIKOLA TESLA adoraba los NÚMEROS 369 ? ( Descodificando el Universo Energético) [Vídeo]. Recuperado el 2 de julio de 2018 de https://www.youtube.com/watch?v=xCb3KXPdLKs

Robben, A. (2017). Death, Mourning, and Burial: A Cross-Cultural Reader. Hoboken, NJ: Wiley-Blackwell.

Sánchez Montalbán, A. (2009). Cómo nació Agartam [Mensaje en una página web]. Recuperado el 10 de julio de 2018 de http://www.agartam.com/web.html

Sánchez Montalbán, A. (2018). Aprender a canalizar. Recuperado el 28 de noviembre de 2018 de https://www.aprenderacanalizar.com/cursos-presenciales/aprender-acanalizar/

Revista Cultura \& Religión Vol. XIII, 2019 № 2 (julio-diciembre)

Cómo citar este artículo: Pastor-Talboom, S. (2019). "La red y los círculos de Ánima. Orígenes, doctrina y

sistematización de sus fuentes”. Revista Cultura \& Religión.13(2). pp. 30-51. 
Sánchez Montalbán, A. \& Polo, V. (2016). Hermanos del bajo astral. Almería: Editorial Círculo Rojo.

Sánchez Nogales, J. L. (1997). La nostalgia del eterno. Sectas y religiosidad alternativa. Madrid: CCS.

Setright, A. (2014). "Ecofeminismo: sabiduría antigua para una Nueva Era". Orbis. Revista Científica Ciencias Humanas, 10(1), pp. de 50 a 63, visitado el 1 de junio de 2018. (http://www.redalyc.org/pdf/709/70930408003.pdf)

Sotomayor, J. (2017). Geometría Sagrada - Akenaton La ley de Uno [Vídeo]. Recuperado el 23 de junio de 2018 de https://www.youtube.com/watch?v=M6ZOTKrbOY0

Sutcliffe, R. (1996). "Left Hand Path Ritual Magic". En Pagan Pathways (pp. 109-137). C. Hardman \& G. Harvey (Ed.). Londres: Thorsons.

Thomas, L.-V. (1983). Antropología de la muerte. México: Fondo de Cultura Económica.

Turner, E. (2003). "The Reality of Spirits". En Shamanism: A Reader (p. 146). G. Harvey (Ed.). London. Routledge.

Weiss, B. (2005). Muchos cuerpos, una misma alma. Barcelona: Zeta. 